\title{
Clinical Characteristics of Elderly Acute Ischemic Stroke Patients Calling Emergency Medical Services
}

\author{
In Hwan Lim ${ }^{1, *}$, Hyung Jong Park ${ }^{2, *}$, Hyun Young Park ${ }^{1}$, Kyeong Ho Yun ${ }^{3}$, Dae-Han $\mathrm{Wi}^{4}$, Young-Hoon Lee \\ ${ }^{1}$ Department of Neurology, Wonkwang University School of Medicine, Institute of Wonkwang Medical Science and Regional \\ Cardiocerebrovascular Center, Iksan, ${ }^{2}$ Department of Neurology, Yonsei University College of Medicine, Seoul, ${ }^{3}$ Department of \\ Cardiovascular Medicine, Wonkwang University School of Medicine, Iksan, ${ }^{4}$ Department of Emergency Medicine, Wonkwang University \\ Sanbon Medical Center, Gunpo, ${ }^{5}$ Department of Preventive Medicine, Wonkwang University School of Medicine and Regional \\ Cardiocerebrovascular Center, Iksan, Korea
}

Corresponding Author: Hyun Young Park, MD Department of Neurology, Wonkwang University School of Medicine \& Hospital, 895 Muwang-ro, Iksan 54538, Korea

Tel: $+82-63-859-1410$ Fax: +82-63-842-7379

E-mail: hypppark@hanmail.net "These authors contributed equally to this study and should be considered co-first authors.

Received: July 26, 2017

Revised: December 13, 2017 Accepted: December 19, 2017

\begin{abstract}
Background: Time is the most important determining factor in acute ischemic stroke (AIS) treatment. Calling emergency medical services (EMS) during an AIS can reduce the time until treatment. Although differences in clinical characteristics, including sex, have been studied in patients with acute coronary syndrome, limited data are available on the differences among patients with AIS who call EMS, especially elderly patients. Methods: Patients aged 65 years or older who had received a diagnosis of AIS within 1 week of hospitalization were recruited and analyzed within 24 hours after symptom onset between January 1, 2012 and December 31, 2015. Calls to EMS was assessed by self-report during an in-hospital interview and verified using structured chart reviews to determine clinical differences among patients calls to EMS. Results: Of the 1,002 patients studied, 414 patients (41.3\%) called EMS. A similar percentage of women and men with AIS called EMS (43.1\% and 39.3\%, respectively). The group calls to EMS had a faster median arrival time at the hospital (159 minutes vs. 793 minutes) and higher National Institutes

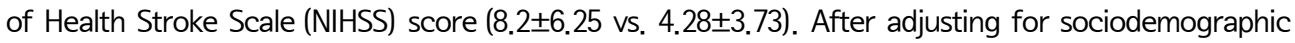
factors, EMS users were found to have shorter median onset-to-door time and higher NIHSS scores (odds ratio [OR], 3.538; 95\% confidence interval [Cl], 2.333-5.366; $p<0.01$, and OR, 3.336; $95 \% \mathrm{Cl}, 1.032-10.786 ; \mathrm{p}<0.05$, respectively). Conclusion: Our study suggests that calls to EMS reduces prehospital delay and expedites treatment for stroke. We expect that a wide-ranging and specialized educational program for increasing EMS use and enhancing stroke knowledge will lead to early hospital arrival for all age groups.
\end{abstract}

Key Words: Emergency medical services, Stroke, Education, Prognosis

\section{INTRODUCTION}

Stroke has become a major health problem in Korea". According to a recent report, each year approximately 105,000 people experience a new or recurrent stroke, and more than 26,000 people die from stroke ${ }^{2,3}$. Patients with stroke must be treated immediately to achieve a good outcome and improve neurological prognosis ${ }^{4,5)}$.

Time is the most important determinant in treatment of acute ischemic stroke (AIS), so it is reasonable to regard AIS as a critically time-dependent condition. Nonetheless, based on reports from Assessment for Quality for Acute Stroke Care in Korea, prehospital delay was greater in a group of patients with ischemic stroke than in those with hemorrhagic stroke $^{6,7)}$. Consequently, the proportion of patients who acce- ssed treatment in time to receive intravenous (IV) tissue plasminogen activator (tPA) decreased from $42.0 \%$ in 2008 to $36.3 \%$ in $2010^{6,7)}$. Several studies found that patients who were transported by emergency medical services (EMS) had shorter prehospital delays than did patients who did not use $\mathrm{EMS}^{8-10}$. In addition, increased IV tPA treatment rate is associated with better prognosis than that achieved by patients not using EMS ${ }^{3-5}$. Thus, we speculate that calls to EMS could help solve the problem of prehospital delays, and calls to EMS could be associated with patient prognosis.

Recent studies have mainly examined the factors that lead to delays in the treatment of acute coronary syndrome, focusing particularly on the use of EMS ${ }^{11-14)}$, but there have been few studies regarding the use of EMS use in AIS. Therefore, we focused on the characteristics, clinical differences, and prognoses of patients aged 65 years or older with AIS, 
based on calling or not calls to EMS, to investigate the association between prehospital delay and calls to EMS.

\section{MATERIALS AND METHODS}

For this investigation, we recruited 1,002 patients aged 65 years and over, with a primary diagnosis of AIS within 24 hours from symptom onset, who were directly admitted to the Wonkwang University Hospital Regional Cardiocerebrovascular Center in Iksan city, Korea, between January 1, 2012 and December 30, 2015. All enrolled patients were diagnosed with AIS by magnetic resonance imaging of the brain. Wonkwang University Hospital is the main referral hospital in Iksan city, Korea, for all varieties of stroke and is supported by the Ministry of Health and Welfare. In-hospital interviews of patients with their next of kin or other witnesses were conducted within 48 hours of hospital admission to collect data regarding calls to EMS and to identify initial stroke symptoms and their onset. Structured chart reviews of patient demographic characteristics and medical records were performed. All patients were assessed for stroke severity using the National Institutes of Health Stroke Scale (NIHSS), with scores ranging from 0 to 38 on admission ${ }^{15}$. Modified Rankin Scale (mRS) scores, ranging from 0 to 5 (with 0 for no symptoms, and 5 for severe disability), were assessed in all patients at 90 days after admission. This scale is widely applied in evaluating recovery from stroke ${ }^{16,17)}$.

Symptom onset was defined as the time the patient or any nearby witnesses noticed the symptoms. If the symptoms developed during sleep, time of symptom onset was defined as the time the patient fell asleep. Prehospital delay was evaluated using onset-to-door time, which was defined as the time from symptom onset to arrival at the Emergency Department of our hospital.

Data were analyzed with the chi-square test, independent t-test, and analysis of variance to evaluate univariate associations of categorical variables for all patients and between EMS and non-EMS users. Variables identified from a univariate analysis $(p<0.05)$ among EMS users were considered explanatory variables, and these variables were subsequently adjusted for sociodemographic factors in a multivariate analysis. All test results were considered statistically significant if $p<0.05$. All analyses were performed using SPSS ver. 17.0 (SPSS Inc., Chicago, IL, USA).

\section{RESULTS}

Of the 1,002 patients studied, 414 patients (41.3\%) called EMS. The mean age of the EMS user group was $77.28 \pm 6.96$ years. There was no significant difference in the proportion of men and women between the 2 groups. The baseline characteristics of subjects are shown in Table 1.
EMS users had significantly higher NIHSS scores at admission (8.2 \pm 6.25 vs. $4.28 \pm 3.73)$ and a shorter median onset-todoor time (159 minutes vs. 793 minutes) than the non-EMS user group.

With regard to initial stroke symptoms, there tends to be less usage of EMS in cases of sensory symptoms such as paresthesia, which highlights the significance of awareness and knowledge of stroke symptoms in advance. Otherwise, there were no differences between the two groups in marital status, education level, or past history of hypertension or diabetes mellitus.

Table 2 summarizes the adjusted odds ratios (ORs) for significant factors calculated using multivariate logistic regression analysis. After adjusting for sociodemographic factors, shorter arrival time $(\mathrm{OR}, 3.538 ; 95 \%$ confidence interval $[\mathrm{Cl}]$, $2.333-5.366 ; p<0.01)$ and severity of NIHSS (OR, 3.336; 95\% $\mathrm{Cl}, 1.032-10.786 ; p<0.05)$ were associated with greater likelihood of using EMS.

Table 1. Baseline characteristics of study subjects

\begin{tabular}{|c|c|c|c|}
\hline Variable & $\begin{array}{l}\text { EMS user } \\
(n=414)\end{array}$ & $\begin{array}{c}\text { Non-EMS } \\
\text { user }(n=588)\end{array}$ & p-value \\
\hline Age (yr) & $77.28 \pm 6.96$ & $75.56 \pm 6.45$ & $<0.001$ \\
\hline Male sex & $188(39.3)$ & $290(60.7)$ & 0.388 \\
\hline Marital status, married & $272(41.6)$ & $382(58.4)$ & 0.837 \\
\hline Education level ( $\geq 12 \mathrm{yr}$ ) & $126(39.4)$ & $194(60.6)$ & 0.396 \\
\hline Residential region, urban & $242(44.2)$ & $306(55.8)$ & 0.156 \\
\hline History of CV events & $114(45.6)$ & $136(54.4)$ & 0.262 \\
\hline Hypertension & $296(40.9)$ & $428(59.1)$ & 0.751 \\
\hline Diabetes mellitus & $110(37.7)$ & $182(62.3)$ & 0.288 \\
\hline Dyslipidemia & $156(36.4)$ & $272(63.6)$ & 0.056 \\
\hline \multicolumn{4}{|l|}{ Type of initial symptoms } \\
\hline Hemiparesis & $208(44.1)$ & $262(55.9)$ & 0.238 \\
\hline Sensory change & $6(10.7)$ & $50(89.3)$ & $<0.001$ \\
\hline Speech disorders & $144(40.4)$ & $212(59.6)$ & 0.770 \\
\hline Mental changes & $46(54.8)$ & $38(45.2)$ & 0.067 \\
\hline Headache & $8(30.8)$ & $18(62.9)$ & 0.426 \\
\hline Other* & $2(25.0)$ & $6(75.0)$ & 0.493 \\
\hline Arrival time $(<3 \mathrm{hr})$ & $266(61.0)$ & $170(39.0)$ & $<0.001$ \\
\hline Median arrival time (min) & 159.0 & 793.5 & 0.020 \\
\hline NIHSS & & & $<0.001$ \\
\hline Mild (1-4) & $162(27.6)$ & $426(72.4)$ & \\
\hline Moderate (5-15) & $200(57.1)$ & $150(42.9)$ & \\
\hline Severe $(\geq 16)$ & $52(81.3)$ & $12(18.8)$ & \\
\hline NIHSS at admission day & $8.2 \pm 6.25$ & $4.28 \pm 3.73$ & $<0.001$ \\
\hline $\mathrm{mRS}$ at 90 days later & $2.1 \pm 1.48$ & $1.41 \pm 0.99$ & $<0.001$ \\
\hline
\end{tabular}

Values are presented as mean \pm standard deviation or number (\%). EMS, emergency medical services; CV, cerebrovascular; NIHSS, National Institutes of Health Stroke Scale; mRS, modified Rankin Scale.

*Other: visual disturbance or seizure. 
In Hwan Lim, et al.

Table 2. Logistic regression analysis of clinical factors associated with calls to EMS

\begin{tabular}{lcr}
\hline \hline Variable & Odds ratio (95\% CI) & p-value \\
\hline Age & $1.008(0.977-1.040)$ & 0.618 \\
Arrival time $(<3 \mathrm{hr})$ & $3.538(2.333-5.366)$ & $<0.001$ \\
Type of initial symptom & & \\
$\quad$ Sensory change & $0.306(0.088-1.069)$ & 0.064 \\
\hline NIHSS & - & - \\
$\quad$ Mild $(1-4)$ & $2.214(1.352-3.628)$ & 0.002 \\
$\quad$ Moderate $(5-15)$ & $3.336(1.032-10.786)$ & 0.044 \\
\hline
\end{tabular}

EMS, emergency medical services; CI, confidence interval; NIHSS; National Institutes of Health Stroke Scale.

\section{DISCUSSION}

An association between early hospital arrival and the use of EMS has been reported in several studies ${ }^{8,18-22)}$. Those studies were conducted to assess factors that could determine or influence prehospital delays so that neurological outcomes in stroke patients could be improved by reducing such delays. In the present study, EMS users had significantly shorter prehospital delays than did non-EMS users, consistent with the findings of previous studies ${ }^{23-25)}$. When we first analyzed 2,746 patients who were admitted with AIS within 24 hours from symptom onset between January 1, 2012 and December 30, 2015, we found that elderly patients over 65 years of age were significantly more likely to use EMS, and EMS users were more likely to arrive sooner at the hospital (data not shown). The main explanations for these findings were that, in comparison to younger age groups, the elderly have fewer transportation options and a higher percentage of these individuals live alone ${ }^{14)}$. Based on these findings, the present study was performed to investigate the determinants of use of EMS in patients with AIS aged 65 years and over.

Another finding of our study regarded differences in initial stroke symptoms and stroke severity. Statistically, EMS usage in the present study was in proportion to the severity level of unconsciousness and/or NIHSS score, similar to the findings of previous studies ${ }^{18,25)}$; thus, awareness of stroke warning signs is important. This result suggests that a community-based program is strictly required in the near future to improve public awareness of the warning signs of stroke. Considering mRS scores in 90 days, the non-EMS user group seemed to have a better result regarding difference in $\mathrm{mRS}$, but considering the initial NIHSS scores of the two groups, early arrival at the hospital and prompt treatment owing to EMS use appears to improve patient prognosis, especially in elderly patients with severe symptoms. The association between patients' EMS use and neurological outcomes re- mains unclear ${ }^{6,22,26)}$; further investigation will thus be required to elucidate this association.

In the current study, consistent with the findings of previous studies, sex, education level, and the presence of comorbidities that are risk factors for stroke, such as hypertension and diabetes, were not associated with the use of $\mathrm{EMS}^{6,20,27-29)}$. In Korea, public knowledge about risk factors for stroke remains poor, and only half of the survey respondents were able to identify at least one stroke risk factor $^{30-32)}$. Thus, patients who have a history of these risk factors may still lack knowledge of their importance. That ignorance, in turn, could influence their likelihood of using EMS. Other studies have reported that a negative prior experience with hospitals or physicians is an influential factor in the use of $\mathrm{EMS}^{33}$. Although we did not examine the family interview for information regarding education level or awareness and knowledge of stroke warning signs, we strongly suggest that it is important to facilitate education to enhance the awareness and knowledge of stroke, thereby decreasing the time to arrival at the hospital by calls to EMS.

In conclusion, this was a community-based study performed to investigate the clinical characteristics and other factors associated with EMS use in Korea. We suggest that greater use of EMS by elderly individuals with severe symptoms could reduce prehospital delays and expedite treatment for AIS. Based on the findings of this study, we expect that a wide-ranging, and specialized educational program aimed at increasing EMS use and enhancing stroke knowledge will lead to earlier hospital arrival for all age groups.

Conflicts of Interest Disclosures: The researchers claim no conflicts of interest.

\section{Acknowledgments}

This work was supported by the Wonkwang Research Grant in 2016. The authors thank Hangha Kim of Iksan High School for statistical help with this study.

\section{REFERENCES}

1. Seok J, Lee JS, Jeong KY, Choi HS, Hong HP, Ko YG. Association between blood pressure after thrombolysis and neurolgocial outcome in the elderly patients with ischemic stroke. Ann Geriatr Med Res 2016;20:195-203.

2. Korea Centers for Disease Control and Prevention. Construction of national surveillance system for cardiovascular \& cerebrovascular diseases. Cheongju: Korea Centers for Disease Control and Prevention; 2006.

3. Hong KS, Bang OY, Kang DW, Yu KH, Bae HJ, Lee JS, et al. Stroke statistics in Korea: part I. Epidemiology and risk factors: a report from the korean stroke society and clinical research center for stroke. J Stroke 2013;15:2-20. 
4. Marler JR, Tilley BC, Lu M, Brott TG, Lyden PC, Grotta JC, et al. Early stroke treatment associated with better outcome: the NINDS rt-PA stroke study. Neurology 2000;55:1649-55.

5. Lees KR, Bluhmki E, von Kummer R, Brott TG, Toni D, Grotta JC, et al. Time to treatment with intravenous alteplase and outcome in stroke: an updated pooled analysis of ECASS, ATLANTIS, NINDS, and EPITHET trials. Lancet 2010;375: 1695-703.

6. Health Insurance Review \& Assessment Service. Report of assessment for quality of acute stroke care in Korea. Wonju (Korea): Health Insurance Review \& Assessment Service; 2008.

7. Health Insurance Review \& Assessment Service. Report of assessment for quality of acute stroke care in Korea. Wonju (Korea): Health Insurance Review \& Assessment Service; 2010.

8. Wester P, Rådberg J, Lundgren B, Peltonen M. Factors associated with delayed admission to hospital and in-hospital delays in acute stroke and TIA: a prospective, multicenter study. SeekMedical-Attention-in-Time Study Group. Stroke 1999;30:40-8.

9. Hong KS, Bang OY, Kim JS, Heo JH, Yu KH, Bae HJ, et al. Stroke statistics in Korea: Part II stroke awareness and acute stroke care, a report from the Korean Stroke Society and Clinical Research Center For Stroke. J Stroke 2013;15:67-77.

10. Hur JW, Jo IJ, Sim MS, Song HG. Factors influencing prehospital and inhospital time delays for ischemic stroke patients. J Korean Soc Emerg Med 2011;22:193-9.

11. Hutchings CB, Mann NC, Daya M, Jui J, Goldberg R, Cooper $\mathrm{L}$, et al. Patients with chest pain calling 9-1-1 or self-transporting to reach definitive care: which mode is quicker? Am Heart J 2004;147:35-41.

12. Johansson I, Strömberg A, Swahn E. Ambulance use in patients with acute myocardial infarction. J Cardiovasc Nurs 2004;19: $5-12$.

13. Canto JG, Zalenski RJ, Ornato JP, Rogers WJ, Kiefe CI, Magid $\mathrm{D}$, et al. Use of emergency medical services in acute myocardial infarction and subsequent quality of care: observations from the National Registry of Myocardial Infarction 2. Circulation 2002; 106:3018-23.

14. Brown AL, Mann NC, Daya M, Goldberg R, Meischke H, Taylor $\mathrm{J}$, et al. Demographic, belief, and situational factors influencing the decision to utilize emergency medical services among chest pain patients. Rapid Early Action for Coronary Treatment (REACT) study. Circulation 2000;102:173-8.

15. Brott T, Adams HP Jr, Olinger CP, Marler JR, Barsan WG, Biller $\mathrm{J}$, et al. Measurements of acute cerebral infarction: a clinical examination scale. Stroke 1989;20:864-70.

16. Rankin J. Cerebral vascular accidents in patients over the age of 60. II. Prognosis. Scott Med J 1957;2:200-15.

17. van Swieten JC, Koudstaal PJ, Visser MC, Schouten HJ, van Gijn J. Interobserver agreement for the assessment of handicap in stroke patients. Stroke 1988;19:604-7.

18. Schroeder EB, Rosamond WD, Morris DL, Evenson KR, Hinn
AR. Determinants of use of emergency medical services in a population with stroke symptoms: the Second Delay in Accessing Stroke Healthcare (DASH II) Study. Stroke 2000;31:2591-6.

19. Kothari R, Jauch E, Broderick J, Brott T, Sauerbeck L, Khoury $\mathrm{J}$, et al. Acute stroke: delays to presentation and emergency department evaluation. Ann Emerg Med 1999;33:3-8.

20. Rosamond WD, Gorton RA, Hinn AR, Hohenhaus SM, Morris DL. Rapid response to stroke symptoms: the Delay in Accessing Stroke Healthcare (DASH) study. Acad Emerg Med 1998;5:4551.

21. Menon SC, Pandey DK, Morgenstern LB. Critical factors determining access to acute stroke care. Neurology 1998;51:427-32.

22. Williams LS, Bruno A, Rouch D, Marriott DJ. Stroke patients' knowledge of stroke. Influence on time to presentation. Stroke 1997;28:912-5.

23. Lacy CR, Suh DC, Bueno M, Kostis JB. Delay in presentation and evaluation for acute stroke: Stroke Time Registry for Outcomes Knowledge and Epidemiology (S.T.R.O.K.E.). Stroke 2001;32:63-9.

24. Barsan WG, Brott TG, Broderick JP, Haley EC, Levy DE, Marler JR. Time of hospital presentation in patients with acute stroke. Arch Intern Med 1993;153:2558-61.

25. Kwan J, Hand P, Sandercock P. A systematic review of barriers to delivery of thrombolysis for acute stroke. Age Ageing 2004; 33:116-21.

26. Zweifler R, Taft B, Lyden P, Rothrock J. Relationship between time to medical evaluation and ischemic stroke severity: the UCSD Stroke Data Bank. J Stroke Cerebrovasc Dis 1995;5:111.

27. Chang KC, Tseng MC, Tan TY. Prehospital delay after acute stroke in Kaohsiung, Taiwan. Stroke 2004;35:700-4.

28. Morris DL, Rosamond W, Madden K, Schultz C, Hamilton S. Prehospital and emergency department delays after acute stroke: the Genentech Stroke Presentation Survey. Stroke 2000;31: 2585-90.

29. Feldmann E, Gordon N, Brooks JM, Brass LM, Fayad PB, Sawaya $\mathrm{KL}$, et al. Factors associated with early presentation of acute stroke. Stroke 1993;24:1805-10.

30. Kim YS, Park SS, Bae HJ, Heo JH, Kwon SU, Lee BC, et al. Public awareness of stroke in Korea: a population-based national survey. Stroke 2012;43:1146-9.

31. Kim JS, Yoon SS. Perspectives of stroke in persons living in Seoul, South Korea. A survey of 1,000 subjects. Stroke 1997;28: 1165-9.

32. Lee $\mathrm{YH}$, Shin MH, Kweon SS, Choi JS, Park MS, Cho KH, et al. Awareness of stroke warning signs and risk factors: result of a 2010 community survey in Gwangju Metropolitan city. J Korean Neurol Assoc 2012;30:26-32.

33. Bae HJ, Yoo KM, Yoon BW, Kim J, Kim JY, Kim EG, et al. Stroke awareness in Korea: The Results of Survey in the Second Stroke Prevention Campaign. J Korean Neurol Assoc 2002;20: 110-7. 